\title{
Internet Addiction and its Correlation with Depression, Anxiety, Stress, and Loneliness in Undergraduate Students of UIN Malang
}

\author{
Mely Santoso ${ }^{1 *}$,Fathul Lubabin Nuqul ${ }^{2}$, Gisni Rabiah Aqilah ${ }^{3}$. \\ 1.2.3. Department of Psychology, Universitas Islam Negeri Maulana Malik Ibrahi, Malang, Indonesia \\ *E-mail: melysantoso94@gmail.com
}

\begin{abstract}
The arrival of the internet in addition brings positive impacts such as facilitate communication. However, it also brings negative impacts. One of the negative impact brought by the technological development is the phenomenon called internet addiction that has been widely studied. This study aims to find the relationship between internet addiction with depression, anxiety, and stress. A total of 166 UIN Malang undergraduate students were selected as research subjects. Each of the subjects were given IAT scale, DASS-42, and UCLA Loneliness scale to measure each variable of the research. We asked the participants to fill in the questionnaires, including the demographic characteristic of the internet they use such as the device they use for accessing the internet, the provider they use, the reason they access the internet and so on. Pearson correlation conducted found that there is a correlation between internet addiction, depression $(r=.32, \mathrm{p}<0.05)$, anxiety $(r=.39, \mathrm{p}<0.05)$, stress $(r=.39, \mathrm{p}<0.05$, and loneliness $(r=.19, \mathrm{p}<0.05)$. The correlation score of internet addiction and loneliness are quite small; this is because of the culture diversity among the subjects. These correlation results indicate that people with internet addiction tend to have depression, anxiety, stress, and loneliness.
\end{abstract}

Keywords: internet addiction; depression; anxiety; stress; loneliness.

\section{Introduction}

The Internet has become a human necessity in this modern era. The development of smartphone technology that increasingly sophisticated makes every people has easy access to online contents. With the ease of internet access, some initiative and creative ideas began to come up, especially in the field of trade, e-commerce, and services based on online application. Online buying and selling websites, online transportation service, and various payment systems and bank transactions that can be done through internet-connected smartphones are the examples of the convenience offered from the development of Internet-based information technology.

A survey conducted by the Indonesia Internet Service Provider Association or Asosiasi Penyelenggara Jasa Internet Indonesia (APJII) in 2016 found that 132.7 million Indonesians have become internet users by 2016 from the total population of 256.2 million Indonesians. These results also show an increase in internet users in
Indonesia from 2014 by 51.8 percent. In 2014 internet users amounted to 88 million people and in 2013 internet users in Indonesia amounted to 71.19 million (APJII, 2014).

The survey conducted by APJII (2016) above also found that university students are the most internet users than students or workers. This is because the students used the internet to access journals and articles both nationally or internationally. Students' needs on internet access are also inseparable from the importance of the information provided online. Instant messaging applications like BBM, WhatsApp, and Line are useful social media for giving or exchanging information. These needs make the students become the largest internet users in Indonesia.

Ease of internet access using a smartphone is one of the factors that influence the rise of internet users. Facebook became the most visited social media content by internet users in Indonesia (APJII, 2016). As a rich and accessible source, the internet carries implications for cognitive, emotional, and adolescent 
behavior, and it may bring about drastic changes in various aspects of personal and social life.

Besides its positive side, the internet also contains a negative side because it can trigger bad impact for internet users. The ease access to the internet can bring the users to abuse. For example, there are many internet contents containing elements of pornography and violence. Also, unwise internet users can fall into online games that will waste their time. Use of the internet with a lot of frequencies can cause a person to experience what is currently referred as internet addiction.

Internet addiction is a theme in the study of psychology caused by the emergence of the internet in the late of 20th century. The first empirical study on internet addiction was conducted in 1996 by Young, a pioneer and the proponent who took the problem seriously (Jiang \& Leung, 2012). Internet addiction brings up a lot of debate, so there is still a lot of tasks for clinicians and psychologists to investigate more deeply about this phenomenon. By referring to the pathological gambling criteria in the Diagnostic and Statistical Manual of Mental Disorders 4th Edition (DSM-IV) Young defines internet addiction as an impulse-control disorder which does not involve an intoxicant (Jiang \& Leung, 2012; Young \& Rodgers, 1998).

Many countries, such as South Korea, China, and America, see internet addiction as a serious problem. They recognized this phenomenon is a nationwide problem and there is must be preventive step to handle this phenomenon (Jap et al., 2013)

No consensus exists on the operational definition and diagnostic criteria for internet addiction in the Diagnostic and Statistical Manual of Mental Disorders (DSM-IV) and in International Classification of Diseases (ICD-10) (Ha \& Hwang, 2014). Consequently, the term internet addiction is used interchangeably with terms such as internet dependence, compulsive internet use, problematic internet use, and internet use disorder (Ostovar et al., 2016).

Although there are many terms described by earlier researchers, there is no standard definition for describing the dependence phenomenon to the internet. Several studies had been carried out to establish a diagnostic criteria for internet addiction. Young proposed diagnostic criteria for internet addiction such as withdrawal, poor planning abilities, tolerance, preoccupation, impairment of control, and excessive online time were defined as core symptoms (Younes et al., 2016).
Other researchers found another criterion of internet addiction, as Wu, Lee, Liao, \& Chang (2015) found the signs and symptoms include: a) use internet longer than intended, b) preoccupation with the internet, c) withdrawl symptoms when unable to access the internet, d) unsuccessful attempts to stop or reduce internet use, e) craving, f) loss of interest hobbies or activities ither than the internet, g) excessive internet use depite the knowledge of related problems, g) use of the internet to escape or relieve a negative mood, and $\mathrm{h}$ ) lying about internet use. The types of activity involved IA include online gaming, social networking, online gambling, online shopping, virtual sex, and information overload $(\mathrm{Wu}$, Lee, Liao, \& Chang, 2015)

According to previous research, Young (2004) found that Internet addiction has a negative impact in various aspects of social life. One of them in the academic field. Undergraduate students need to use internet for completing various university tasks and also for getting information about lectures and so forth. This can be bad if students can not control internet usage. University students with problematic internet use may exhibit symptoms of impaired physical health, psychological distress, anxiety, attention deficit and hyperactivity disorder, and behavioral problems (e.g., substance abuse and behavioral addictions, aggression, self-injurious behaviors) (Li et al., 2016).

According to Young (2015 in Internet Addiction) risk factors raised from individuals experiencing Internet addiction can be divided into three; 1 ) social factors, such as poor communication skills that can also lead to poor self-esteem, feel alienated, and may cause additional problems such as difficulty working in groups, 2 ) Psychological factors, such as stress, depression, anxiety, and other psychological problems and 3) biological factors such as sleep difficulty an others. In Psychological factor, Young divide internet addiction into two categories. The first is a double diagnosis on Internet addicts (dually diagnosed internet addict). Internet addicts who suffer from psychological problems such as depression, anxiety, obsessive-compulsive disorder, or substance abuse, to name a few syndromes associated with the disorder. The second referred to as new internet addicts, has no history of mental illness or addiction, and their addiction to the internet is very new.

Earlier research showed that internet addiction is a predictor of stress, depression, anxiety, stress, and loneliness. That study also showed that risk of internet addiction is higher in males than in females (Ostovar et al., 2016). Another study also found that 
there is a significant correlation between potential internet addiction and insomnia, stress, anxiety, depression, and self-esteem. Insomnia, depression, anxiety, and stress sub-scores were higher, and selfesteem was lower in students with potential IA (Younes et al., 2016).

The objectives of this study were to assess demographic characteristic for research participant and to assess the relationship between internet addiction, depression, anxiety, stress and loneliness in UIN Malang Undergraduate students. It is hypothesized that there is a correlation among research variables at undergraduate students of UIN Malang.

\section{Methods}

Sample. The research participants were undergraduate students from Universitas Islam Negeri Malang which is active internet users for daily activities and for studying. The total number of study participants was 166 undergraduate students with $37.3 \%$ male students (62 students) and $62.7 \%$ female students (104 students). The age of the study participants ranged from 16 to 23 years. The samples are taken from several faculties in UIN Malang.

Research Design. This research uses quantitative method. Data were collected using four scales that each measured internet addiction, depression, anxiety, stress, and loneliness. Four scales used in this study are explained below.

\section{Instrument and Measurement}

Internet Addiction Test (IAT). IAT is a scale that measures internet addiction. This scale has been developed by Kimberly S. Young from eight-item of internet addiction scale. The instrument contains 20 items and is divided into six indicators or subscales (salience, excessive use, neglect of work, anticipation, self-control, and neglect of social relationship). Each item is measured using six Likert scales, ranging from 0 (never) to 5 (very often / always). The reliability of this scale has been tested before conducting correlation result. The reliability score of Cronbach's Alpha is 0.868 .

Depression Anxiety and Stress Scale 42 (DASS42). DASS-42 contains 42 items and measures three dimensions separate from negative emotions that include depression, anxiety, and stress. Each of the three dimensions has 14 items, and each item is judged using four Likert scales ranging from 0 (Not me at all, or never.) to 3 (very appropriate to me, or very often). The Indonesian version of DASS-42
Scale is translated by Damanik which has been tested the reliability and validity of the scale.

UCLA Loneliness Scale Version 3.Loneliness is measured using UCLA Loneliness Scale version 3 scale which has 20 items. This scale uses four rangescale from 1 (never) to 4 (often or always). This scale has the value of 11 favorable items and 9 unfavorable items.

Procedure. Each research subject fills the scale with the instructions mentioned on the scale. The scale will then be scored using the scoring procedure of each scale. The collected data was analyzed using SPSS 23. Descriptive statistical test was performed to analyze demographic data and Pearson correlation was performed to find the relationship between variables.

\section{Results}

\section{The socio-demographic characteristics of study} participants

A total of 166 UIN Malang students became participants in the study. The result of descriptive statistic analysis showed that male participants were 62 students (37.3\%) and female participants were 104 students $(62.7 \%)$. Participant age ranged from 16 to 23 years. The participants were taken from several faculties, 30 students $(18.7 \%)$ from the Faculty of Tarbiyah and Teacher Training, 22 students (13.3\%) the Faculty of Science and Technology, 9 students (5.4\%) from the Faculty of Sharia, 84 students $(50.6 \%$ from the Faculty of Psychology, 9 students $(5.4 \%)$ from the Faculty of Economics, 10 students $(6.0 \%)$ from the Faculty of Humanities and 1 student $(0.6 \%)$ did not answer the question.

Researchers add several questions to explore the demographic aspects of the respondents that include:

1. Which is more frequent internet access, using smartphone or WiFi?

2. Is there a $\mathrm{WiFi}$ connection in your residence?

3. Which of the more frequent, internet access using WiFi or Data Package?

4. What is your reason to access internet?

5. What social media are you most often visiting or using? 
Here are the result from five questions with diagrams on each answer;

1. Which is more frequent, internet access using smartphone or WiFi?

The result showed that $143(86.1 \%)$ students more often online using smartphones, $12(7.2 \%)$ students more often online using laptop, 4 (2.4\%) students use both smartphone and laptop for online and 7 $(4.2 \%)$ not answer the question. This means that smartphones are the most device that students use online more often than laptops (Figure 1).

\section{Figure 1.}

Frequency of device most frequently used by subject to online.

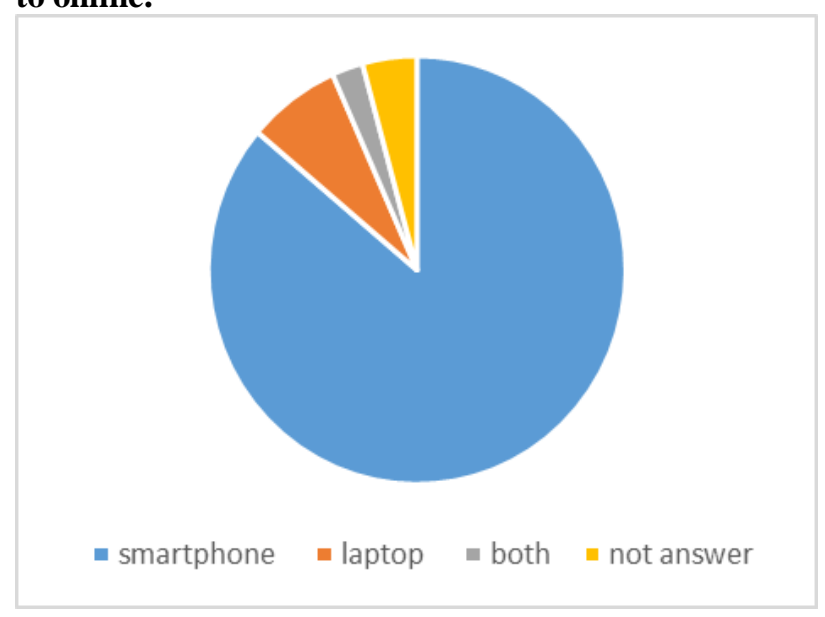

2. Is there WiFi connection in your residence?

The results showed that 107 (64.5\%) of the students answered there was $\mathrm{WiFi}$ access at their residence, $56(33.7 \%)$ students answered there was no WiFi in their residence, and 3 (1.8) students did not answer (Figure 3).

\section{Figure 2.}

The existence of wifi connection in the residence.

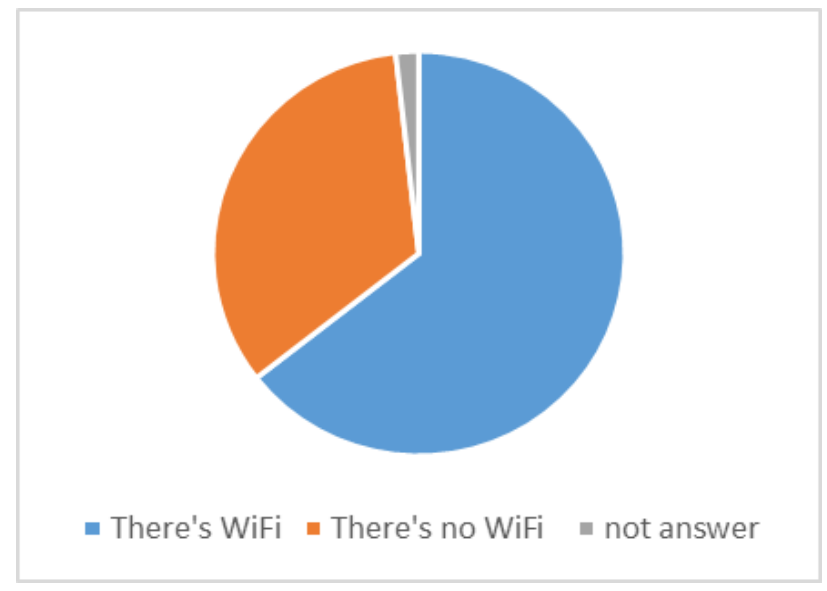

3. Which one more frequent, accessing internet using WiFi or Mobile Data?

The results showed that $95(57.2 \%)$ students are more frequently using mobile data connections, 59 $(35.5 \%)$ were more likely to use WiFi connections, $8(4.8 \%)$ students used both mobile data or $\mathrm{WiFi}$, and $4(2.4 \%)$ did not answer questions (Figure 4 ).

Figure 3.

Frequency of mobile data or WiFi connection used more frequently for accessing internet.

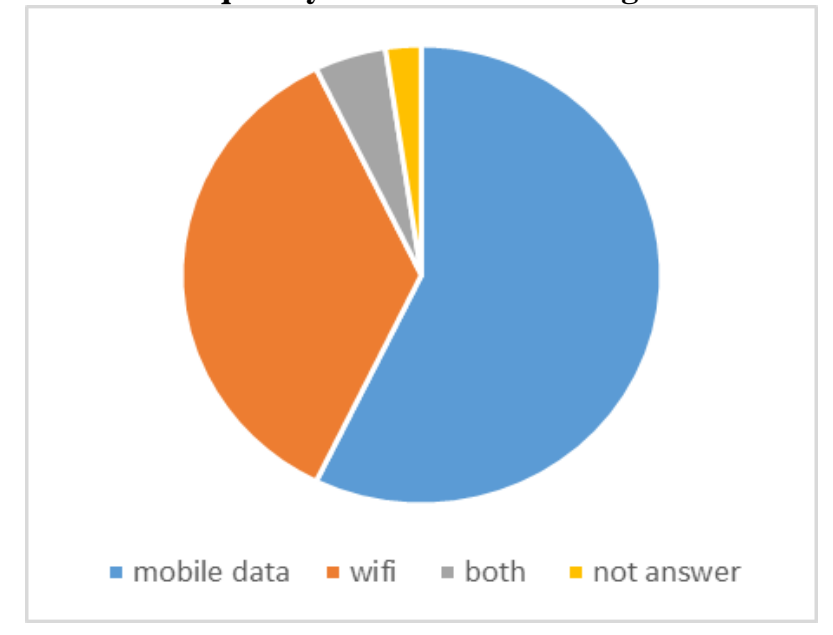

4. What is your reason to access internet?

The results show that $46(27.7 \%)$ of respondents access internet for information updates, 39 (23.5\%) respondents answered for coursework, 32 (19.3\%) respondents answered other reasons, 24 (14.5\%) respondents answered internet access for entertainment, 15 (9.0\%) Respondents answered to fill their spare time, $9(5.4 \%)$ respondents answered for socialization, and $1(0.6 \%)$ did not answer the question posed. Other answers categories include columns that respondents can answer themselves by writing down the reasons for accessing the internet (Figure 5). 
Figure 4.

Subjects reason for accessing internet.

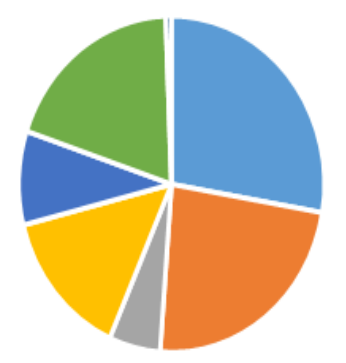

$$
\begin{aligned}
& \text { - Update for information }=\text { College task } \\
& \text { - Socialication } \\
& \text { - For free time } \\
& \text { - not answer }
\end{aligned}
$$

5. What kind of social media are you most visiting or using?

The results of this question showed that 75 (45.2\%) respondents answered Instagram as the most used social media, $25(15.1 \%)$ respondents used Facebook more frequently, $2(1.2 \%)$ respondents use Twitter, and $63(38.0 \%)$ respondents answered Other categories. Other categories include columns that respondents can answer themselves by writing down what kind of social media they used more frequently such as WhatsApp, Line and so on (Figure 6).

\section{Figure 5.}

The social media frequently used by subjects.

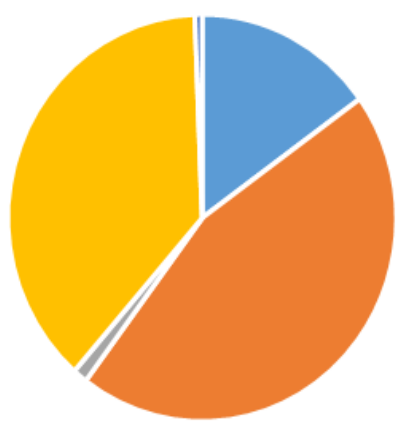

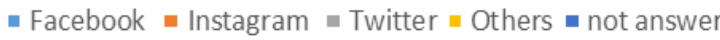

To answer the second research question which is whether there is a relationship between variables, researcher performed Pearson correlation test to see the value of the relationship between each variable.

Table 1 shows the result from Pearson correlation test between internet addiction with depression $(r=$
$0.32, \mathrm{p}<0.05)$, anxiety $(\mathrm{r}=0.39, \mathrm{p}<0.05)$, stress $(\mathrm{r}=$ $0.39, \mathrm{p}<0.05)$, and loneliness $(\mathrm{r}=0.19, \mathrm{P}<0.05)$. From these results can be seen that there is a relationship between internet addiction with depression, anxiety, stress, and loneliness. This means that along with increasing depression, anxiety, stress, and loneliness score, it will also increase the internet addiction score on the subject of research.

On the other hand, the table also showed that depression has positive correlation with anxiety and stress with a high correlation value (anxiety $r=0.76$, $\mathrm{p}<0.05$, stress $\mathrm{r}=0.73, \mathrm{p}<0.05$ ). This means that the higher the depression score will be followed by the high score of anxiety and stress of the subject. A positive relationship with a high correlation value was also found in anxiety with stress $(r=0.80, p$ $<0.05)$ which means higher anxiety score followed by a high-stress score on the subject. While for loneliness variable have relation with enough value with depression $(\mathrm{r}=0.56, \mathrm{p}<0.05)$, anxiety $(\mathrm{r}=$ $0.45, p<0.05)$, and stress $(r=0.50, p<0.05)$, which means higher depression score, Anxiety and stress experienced by the subject will be high as well as the loneliness score of the subject.

Table 1.

Result for Pearson correlation between internet addiction, depression, anxiety, stress, and loneliness.

\begin{tabular}{llllll}
\hline & IA & Dep & Anx & Stre & Lone \\
\hline IA & 1 & & & & \\
& & & & & \\
\hline Dep & $.32 *$ & 1 & & & \\
\hline Anx & $.39 *$ & $.76^{*}$ & 1 & & \\
& & & & & \\
\hline Stre & $.39 *$ & $.73^{*}$ & $.80^{*}$ & 1 & \\
& & & & & \\
\hline Lone & $.19^{*}$ & $.56^{*}$ & $.45^{*}$ & $.50^{*}$ & 1
\end{tabular}

* significant at level 0.05; IA: Internet addiction; Dep: Depression; Anx: Anxiety; Stre: Stress; Lone; Loneliness

From these results found that there is correlation between internet addiction with four other variables although the value of the relationship is varied. The correlation value of internet addiction with anxiety is greater than the correlation value of other variables $(r=0.39, p<0.05)$. On the other hand, the smallest correlation value is found in the correlation between internet addiction with loneliness $(r=0,19, p$ $<0.05)$.

\section{Discussion \& Conclusion}

Discussion. The correlation from the Pearson correlation test on anxiety, stress and depression 
variables included in the category are sufficiently useful to explain the prediction of the result from this study, although it is limited. However, internet addiction relationship with loneliness fall into the category of weak relationships, (Cohen \& Manion, 1994, as cited in Creswell, 2012).

Previous research has found that adolescents and early adults use the internet more often than other age groups with various purposes such as finding entertainment, communicating with friends, internet access for school or college assignments or even accessing the internet to play games (Ostovar et al., 2016). In Indonesia, students are the largest internet users in number compared to other professions or occupations.

The results of this study show a similarity of research results that also found that internet addiction is associated with depression, anxiety, stress, and loneliness at university students (Ostovar et al., 2016; Younes et al., 2016). However, the correlation value between internet addiction and loneliness in this research is quite small in contrast to the findings of Ostovar et al. (2016) which obtained a considerable correlation result.

The different result may be on the cultural side especially in the use of the internet. When accessing the internet, the students do not feel lonely because are looking for friends to chat, therefore they do not feel lonely. This fact is supported by the global statistical data that shows Indonesians spend an average of three hours a day using their social media ("Digital in 2017 Global Overview," n.d.).

Indonesian tends to use social media to interact with others. It is proven in the demographic survey that Instagram is the most widely used social media platform by such as WhatsApp and Line which is an instant messaging application. It is also a factor of low correlation value between internet addiction and loneliness. The social media used to make the students have friends, therefore they do not feel lonely because they can chat with other people.

However, further research is required to prove more strongly result about the relationship between internet addiction, depression, anxiety, stress, and loneliness. In addition to the survey research, perhaps further research can be designed using experiments study to obtain better results by looking at the effects of treatment.

Conclusions. The aims of the research is to measure demographic characteristic of UIN Malang undergraduate students that use or active internet user and to measure correlation value between internet addiction, depression, anxiety, stress, and loneliness. The result shows that there is correlation between each variable of the study (i.e., internet addiction, depression, anxiety, stress, and loneliness). Further research is needed to develop the results of this research.

\section{References}

Asosiasi Penyelenggara Jasa Internet Indonesia (2016). Penetrasi dan perilaku pengguna internet Indonesia. Jakarta. Retrieved December 19, 2016, from https://apjii.or.id/survei

Creswell, J. W. 2012. Educational Research: Planning, Conducting, and Evaluating Quantitative and Qualitative Research (4th Edition). Upper Saddle River, NJ: Pearson Education. Digital in 2017 Global Overview. (n.d.). Retrieved July 29,
2017, https://www.slideshare.net/wearesocialsg/digital-in-2017global-overview

Ha, Y.-M., \& Hwang, W. J. (2014). Gender Differences in Internet Addiction Associated with Psychological Health Indicators Among Adolescents Using a National Webbased Survey. International Journal of Mental Health and Addiction, $12(5), \quad 660-669$. https://doi.org/10.1007/s11469-014-9500-7

Jap, T., Tiatri, S., Jaya, E. S., \& Suteja, M. S. (2013). The development of Indonesian online game addiction questionnaire. PloS One, 8(4), e61098.

Jiang, Q., \& Leung, L. (2012). Effects of Individual Differences, Awareness-Knowledge, and Acceptance of Internet Addiction as a Health Risk on Willingness to Change Internet Habits. Social Science Computer Review, $30(2)$, https://doi.org/10.1177/0894439311398440

Li, W., O’Brien, J. E., Snyder, S. M., \& Howard, M. O. (2016). Diagnostic Criteria for Problematic Internet Use among U.S. University Students: A Mixed-Methods Evaluation. PLOS ONE, 11(1), e0145981. https://doi.org/10.1371/journal.pone.0145981

Montag, C., \& Reuter, M. (Eds.). (2015). Internet Addiction. Cham: Springer International Publishing. https://doi.org/10.1007/978-3-319-07242-5

Ostovar, S., Allahyar, N., Aminpoor, H., Moafian, F., Nor, M. B. M., \& Griffiths, M. D. (2016). Internet Addiction and its Psychosocial Risks (Depression, Anxiety, Stress and Loneliness) among Iranian Adolescents and Young Adults: A Structural Equation Model in a Cross-Sectional Study. International Journal of Mental Health and Addiction, 14(3), 257-267. https://doi.org/10.1007/s11469-015-9628$\underline{0}$

Wu, C.-Y., Lee, M.-B., Liao, S.-C., \& Chang, L.-R. (2015). Risk factors of internet addiction among internet users: an online questionnaire survey. PloS one, 10(10), e0137506.

Younes, F., Halawi, G., Jabbour, H., El Osta, N., Karam, L., Hajj, A., \& Rabbaa Khabbaz, L. (2016). Internet Addiction and Relationships with Insomnia, Anxiety, Depression, Stress and Self-Esteem in University Students: A CrossSectional Designed Study. PLOS ONE, 11(9), e0161126. https://doi.org/10.1371/journal.pone.0161126

Young, K. S. (2004). Internet Addiction: A New Clinical Phenomenon and Its Consequences. American Behavioral 
Scientist, $\quad 48(4)$

https://doi.org/10.1177/0002764204270278

Young, K. S., \& Rodgers, R. C. (1998). Internet addiction: Personality traits associated with its development. In 69th annual meeting of the Eastern Psychological Association

(hal 40-50).

Taken

http://www.netaddiction.com/articles/personality_correlate s-1.pdf 